\title{
Identifiability analysis of nonlinear dynamical system
}

\author{
Zh. Bektemessov \\ al-Farabi Kazakh National University, Almaty, Kazakhstan \\ *e-mail:jolaman252@gmail.com
}

Key words: practical identifiability, dynamical system, parameter estimation, inverse problems

Motivation and Aim: As it is known mathematical modeling plays a huge role in the research of various scientific areas of our life, so ordinary differential equations are a powerful tool for modeling the dynamic processes of biomedicine, especially in modeling the processes of pharmacokinetics, epidemiology and immunology. In practice, it is necessary to determine unknown parameters in the ODE models on the basis of experimental data. Identifiability analysis is the first step in determining them.

Methods and Algorithms: There was considered different approaches of identifiability analysis like drawing contours of the cost functions of least squares $\left(J_{l s q}\right)$ or $(\log -)$ likelihood functions $\left(J_{l l k}\right)$ by pairs of parameters. This will help to determine strong correlation between parameters, non-identifiability for some parameters if the contours extend to infinity. Another approach is the Crammer-Rao inequality based on the relationship between so called Fisher Information Matrix and the covariance matrix. The robust identifiability gives the Monte Carlo based sampling method, which simulates the possibility of performing hundreds of replicates of the same experimental scheme for a given experimental error. Also to solve the inverse problem and restore unknown parameters by the additional information such as experimental data, the algorithm of differential evolution was used.

Results: For the complex two-chamber kinetic model of the C-peptide model with four observables and 8 unknown parameters the mentioned above methods were applied and the next results like lack of identifiability for some of parameters, presence of optimal solutions and good restoration of parameters were obtained.

Conclusion: The results obtained in the model suggest that only two parameters showed practical identifiability, while other parameters were structural and two others illustrated strong correlation and weak identifiability.

Acknowledgements: Supported by the grant of the Ministry of Education and Science of the Republic of Kazakhstan (project No. AP05134121 "Numerical methods of identifiability of inverse and ill-posed problems of natural science")

\section{References}

1. Воронов Д.А., Гроздь А.А. (2014) Идентифицируемость динамических систем на примере моделей фармакокинетики и иммунологии. Новосибирск: Сибирские электронные математические известия. 11:94-104.

2. Cobelli C., Romanin-Jacur G. (1976) Controllability, observability and structural identifiability of multi input and multi output biological compartmental systems. IEEE Trans Biomed Eng 93-100 pp.

3. Kabanikhin S.I., Voronov D.A., Grodz A.A., Krivorotko O.I. Identifiability of mathematical models in medical biology. Vavilovskii Zhurnal Genetiki i Selektsii=Vavilov Journal of Genetics and Breeding. 19(6):738-744. DOI 10.18699/VJ15.097 (in Russian) 